\title{
Spontaneous Remission of Cancer - Enigma and Paradigm
}

\author{
Herbert W. Kappauf \\ Internistische Schwerpunktpraxis, Onkologie - Hämatologie - Psychoonkologie, Starnberg, Germany
}

Spontaneous remission of cancer (SR) is defined as a complete or partial, temporary or permanent disappearance of all or at least some relevant parameters of a soundly diagnosed malignant disease in the absence of medical treatment or with a therapy that does not adequately explain the resulting regression. It is a rare but valid phenomenon which has been observed throughout history of medicine. It represents an instructive in-vivo model of biological tumour control and, remaining enigmatical in most cases, it nevertheless has contributed to paradigmatic shifts in oncology.

Exactly one hundred years ago at the first International Conference on Cancer Research, held in Germany at Heidelberg and Frankfurt, one of the pioneers of modern oncology and founding father of the German Cancer Society Vincenz Czerny gave a still very remarkable key note lecture 'On unexpected recoveries from cancer'[1].

'...I would like to share some observations which show that even in malignant tumours unexpected recoveries do exist and they caution us to ascribe clinical improvement or recovery in such a case exclusively to the used remedy. In animal studies it may be held for ascertained that some, namely smaller tumours are capable of spontaneous regression. [...] In humans off and on cases have been observed in which an apparent worst prognosis proved to be wrong in the further course of disease. Usually a wrong diagnosis was assumed and as one doesn't decide with pleasure to this confession, those observations have been either withheld or told bashfully with a question mark.' And cancer surgeon Czerny finished his lecture: 'In recapitulating we see that without any doubt malignant tumours are capable of regression. Very rarely this happens without a surgical intervention. Sometimes a surgical intervention may accelerate tumour growth due to incomplete destruction of the tumour tissue and thus harm the patient. In other cases with incomplete cancer resection the human organism is enabled to neutralize or even to destroy the residual tumour. We do not know the particulars which make this difference in outcome, but there is no doubt that the pathohistological constitution of the tumours plays a decisive role... But I don't want to be misunderstood that - because of occasional observations of cancer remissions in spite of incomplete resection - I would discredit surgery as early and radical as possible, which hitherto alone made us advance' (translation by H. K.) .

In 2006 Czerny's words are still valid and SR remains a scientifically exciting phenomenon. But surprisingly up to now only two major conferences have dealt with SR as a main topic: In 1974 a conference held at the Johns Hopkins University at Baltimore/USA [2] and in 1997 an international symposium held at the German Centre for Cancer Research (DKFZ) at Heidelberg/Germany [3].

Many scientists are still reluctant to focus their attention on SR. They may fear to jeopardize their academic reputation when dealing with a topic which is often found in catching stories of the yellow press and pamphlets propagating unconventional cancer therapies. In fact, cases of SR are considered to be 'a vital factor in perpetuating many quackery treatmens, whether by "faith healing", machines, holistic nutrition or placebo drugs' [4].

But science learns from reflection on anomalies which help to change paradigms. Historical observations of spontaneous remissions of breast cancer after the onset of menopause lead to approaches of hormonal treatment which nowadays are a mainstay of adjuvant and palliative therapy in breast cancer. Moreover, modern oncological immunotherapy was stimulated by a case of spontaneous remission in a patient with metastatic gastric cancer who survived bacterial peritonitis after resection of the primary and just biopsy of hepatic metastasis [5].

The perception of cancer as a monoclonal uncontrolled proliferation of cells implicitly adhered to a model of a snowball

\begin{tabular}{ll}
\hline KARGER & ( 2006 S. Karger GmbH, Freiburg \\
$\begin{array}{l}\text { Fax +49 } 7614520714 \\
\begin{array}{l}\text { E-mail Information@Karger.de } \\
\text { www.karger.com }\end{array}\end{array}$ & $\begin{array}{l}\text { Accessible online at: } \\
\text { www.karger.com/onk }\end{array}$ \\
&
\end{tabular}

Dr. med. Herbert W. Kappauf Internistische Schwerpunktpraxis

Onkologie - Hämatologie - Psychoonkologie

MediCenter, Oßwaldstr. 1a, 82319 Starnberg, Germany

Tel. +49 8151 559-302, Fax -303

E-Mail onkologie.starnberg@t-online.de 
triggering an avalanche. And avalanches never have been observed to reverse. That is why until this day doubts on the validity of SR have been prevailing even among academic opinion leaders in spite of impeccable case reports. Nowadays we know that accelerated proliferation is not sufficient for cancerogenesis. Proliferating cells have to dodge apoptosis to manifest a malignant tumour [6]. Apoptosis represents a fundamental biological pathway both for ontogenesis and for the maintenance of tissue function and genome stability in every multicellular organism. According to its physiological importance apoptosis is controlled in a very complex way and linked not only with checkpoints of cell proliferation and differentiation but also with angiogenesis/anti-angiogenesis, endocrine modulation, and immunoreactive pathways. In patients with spontaneously regressing tumours malignant cells apparently loose their malignant immortality and become subject to apoptosis again [7]. And case reports of SR in different tumour entities demonstrate that apoptosis in fact may be triggered by endocrine factors, immunoreactive mechanisms associated with viral or bacterial infections, cytotoxic chemotherapy, or transfusion of blood products. Surgical interventions with incomplete tumour resection are part of the medical history of most cases of SR. But only on rare occasions this incomplete resection entails spontaneous regression of the residual tumour. This may be due to a higher antiangiogenic potential in the residual tumour tissue leading to apoptosis [8]. Systematic research on SR has to cope with several methodological difficulties: for instance, patient accrual is somewhat unpredictable when dealing with a rare phenomenon. But the prevalence of SR is quite different in different tumour entities. Anecdotal reports on SR exist for about every type of malignancy but most cases of SR refer to but a few nosological entities: malignant melanoma, renal cell carcinoma, malignant lymphoma, basal cell carcinoma and childhood neuroblastoma. This epidemiological incongruence of cancer prevalence and SR underlines Cerny's statement that the histopathological properties of tumours play an important role in SR.

In frequent malignancies such as lung, colorectal, gastric or cervical cancer SR occurs in less than 1 in 1,000,000 patients. On the other hand metastases of malignant melanoma regress in about 1 in 400 patients and the prevalence of SR in patients with renal carcinoma with only lung metastases may be more than $10 \%$. [10]. With effective innovative treatment options 'wait and see' approaches become more and more exceptional in the management of metastatic disease. Thus the assessment of the prevalence of SR in absence of specific oncological treatment has to be based on incomplete historical data.

Therefore scrupulously documented case reports of SR like the one by Gaussmann et al. [11] in this issue of ONKOLOGIE are very valuable. The case report underlines the importance of continuity of clinical care in order to recognize cases of SR. Probably many cases elude clinical attention in segmented patient care. Research on SR requires a close cooperation of clinicians who observe this phenomenon and basic scientists who may decode the biological pathways of spontaneous tumour regression and may thus reveal new therapeutic strategies.

\section{References}

1 Czerny V: Über unerwartete Krebsheilungen. Z Krebsforschung 1907;3:27-35.

2 Proceedings of a conference held at the Johns Hopkins Medical Institutions, Baltimore, MD, May 9-10, 1974. Baltimore, 1976.

3 Heim M, Schwarz R (eds): Spontanremissionen bei Krebs. Stuttgart, Schattauer, 1998, pp 1-264.

4 Lowy AD Jr, Erickson ER: Spontaneous 19-year regression of oat cell carcinoma with scalene node metastasis. Cancer 1986;58:978-980.

5 Rosenberg SA, Fox E, Churchill WH: Spontaneous regression of hepatic metastases from gastric carcinoma. Cancer 1972;29:472-474.
Gassmann A, Holmgren L, O'Reilly MS, Folkman $\mathrm{J}$ : Dormancy of micrometastasis: Balanced proliferation and apoptosis in the presence of antiangiogenesis suppression. Nature Med 1995;1:149-153.

7 Kaufmann Y, Many A, Rechavi G, Mor O, Biniaminov M, Rosenthal E, Levanon M, Davidsohn J, Aizman I, Mark Z, et al.: Brief report: lymphoma with recurrent cycles of spontaneous remission and relapse - possible role of apoptosis. N Engl J Med 1995;332:507-510.
Kappauf H, Gallmeier WM, Wünsch P, Mittelmeie HO, Birkmann J, Büschel G, Kaiser G, Kraus J: Spontaneous remission of metastases in a patient with non-small cell lung cancer. Ann Oncol 1997;8: 1031-1039.

9 Kappauf H: Wunder sind möglich. Spontanheilung bei Krebs. Freiburg, Herder, 2003, pp 1-192.

10 Gaussmann A, Imhoff D, Lambrecht E, Menzel C, Mose S: Spontaneous remission of metastases of cancer of the uterine cervix. Onkologie 2006;29: $159-161$. 